Portland State University

PDXScholar

$11-9-2019$

\title{
Alignment of Theoretically Grounded Constructs for the Measurement of Science and Chemistry Identity
}

Kathryn Nicole Hosbein

Portland State University, katyhosbein@gmail.com

Jack Barbera

Portland State University, jbarbera@pdx.edu

Follow this and additional works at: https://pdxscholar.library.pdx.edu/chem_fac

Part of the Chemistry Commons, and the Science and Mathematics Education Commons Let us know how access to this document benefits you.

Citation Details

Published as Kathryn N. Hosbein and Jack Barbera, "Alignment of Theoretically Grounded Constructs for the Measurement of Science and Chemistry Identity," Chemistry Education Research and Practice, 2020, 21, 371-386, DOI:10.1039/C9RP00193J.

This Poster is brought to you for free and open access. It has been accepted for inclusion in Chemistry Faculty Publications and Presentations by an authorized administrator of PDXScholar. Please contact us if we can make this document more accessible: pdxscholar@pdx.edu. 


\title{
Alignment of Theoretically Grounded Constructs for the Measurement of Science and Chemistry Identity
}

Hosbein, Kathryn N. \& Barbera, Jack

\begin{abstract}
Identity has been theorized to aid in student persistence within STEM disciplines. In this study, science and chemistry identity were defined as being recognized as a science or chemistry person within the classroom. To generalize the effects that identity has on student persistence, a measurable construct must be defined, operationalized, and tested in multiple settings with different populations. This project addressed the first step in the process, defining the construct and grounding it in an established theoretical framework. This qualitative project utilized a previously described physics identity framework, with subconstructs of performance/competence, recognition, and interest, as a starting point for the alignment of students' perceptions of identity to the broader theoretical frameworks of identity. Nine semi-structured interviews were conducted with students from a range of chemistry courses at Portland State University. The interviews consisted of questions pertaining to the sub-constructs of identity. Thematic analysis was used to define emerging themes within student responses. These themes were found to align with an array of affective constructs, including mastery experiences, verbal persuasion, vicarious experiences, situational interest, and mindset. These constructs will be used to develop an identity measure for chemistry education that is grounded in the broader theoretical frameworks of identity.

\section{Reference Information:}

Kathryn N. Hosbein and Jack Barbera, "Alignment of Theoretically Grounded Constructs for the Measurement of Science and Chemistry Identity," Chemistry Education Research and Practice, 2020, 21, 371-386, DOI:10.1039/C9RP00193J.
\end{abstract}




\section{Introduction}

While students often select their career trajectory before entering college, (Bandura, et al., 2001; Eccles, 2007) there still exists a drastic discrepancy between students entering college with a declared STEM major and graduating with a STEM degree (National Research Council, 2012; President's Council of Advisors on Science and Technology, 2012). This is especially an issue for underrepresented groups of students such as women, black, and Hispanic students (Seymour, et al., 1997; Bonous-Hammarth, 2000; Penner, 2015). One of the proposed mechanisms to increase student persistence within the STEM fields is to foster science identity (Chang, et al., 2011; Estrada, et al., 2011; President's Council of Advisors on Science and Technology, 2012; Graham, et al., 2013; Flowers and Banda, 2016). While identity has been widely proposed to increase persistence within the broad field of STEM, it has also been hypothesized to increase persistence within the more narrow discipline of chemistry (Shedlosky-Shoemaker and Fautch, 2015).

Identity is a complex psychological construct that can be individually (Burke and Stets, 2009) or socially (Abrams and Hogg, 1990) constructed. An individual can have multiple identities based on characteristics such as race (Sellers, et al., 1998), gender (Lorber, 1994; Davidoff and Hall, 2013) and social status (Davidoff and Hall, 2013). Therefore, when studying identity, it is crucial to ground identity within the specific context under study (Brickhouse, et al., 2000). In 2000, James Paul Gee proposed that identity be used as a lens to study education and defined the construct in the following manner:

Being recognized as a certain "kind of person," in a given context, is what I mean here by "identity." In this sense of the term, all people have multiple identities connected not to their "internal states" but to their performances in society. This is not to deny that each of us has what we might call a "core identity" that holds more uniformly, for ourselves and others, across contexts (p. 99)."

Through this definition, science identity can be defined as “being recognized as a 'science person', in a science context", such as a classroom. Chemistry identity can similarly be defined as "being recognized as a 'chemistry person' in a chemistry context".

Building upon Gee's definition of identity, Carlone \& Johnson (2007) proposed a science identity theory that contained three sub-constructs involved in identity formation for women of color through their late college and early career paths: performance, competence, and recognition (Figure 1A). Performance 
was defined as "social performance of relevant scientific practices - e.g., ways of talking and using tools." Competence was defined as "knowledge and understanding of science content (may be less publicly visible than performance)." Recognition was defined as "recognizing oneself and getting recognized by others as a 'science person."' The three constructs were hypothesized to work together such that a person would perform tasks in a science context that illustrate their competence and, in this way, the individual would be recognized by others as a credible science person. This theory accounts for the socially (as opposed to individually) constructed nature of science identity, as there are certain societal norms associated with science performance, competence, and recognition and therefore the theory assumes that one's racial, ethnic, and gender identity may overlap with one's science identity. While the Carlone \& Johnson (2007) study developed a more clearly defined science identity theory through a qualitative viewpoint, it could not be generalized to larger populations because it was developed around a very specific population.

To generalize the effects that identity has on one's persistence, a measurable construct must be established and tested in multiple settings with different populations. Additionally, to support the validity of measured data, the measure needs to be operationalized specifically for its intended use. There are existing science and discipline-specific identity measures within the education literature, however, they have been operationalized to roles other than "science person", such as "scientist" identity (Chemers, et al., 2011; Estrada, et al., 2011) and "science student" identity (Stets, et al., 2017) or have been operationalized specifically to physics (Hazari, et al., 2010; Cass, et al., 2011; Godwin and Potvin, 2013; Vincent-Ruz and Schunn, 2018), math (Cass, et al., 2011), or science (Vincent-Ruz and Schunn, 2018). Brickhouse et al., (2000) has stressed the importance of studying appropriate communities of practice in which identities can form. For example, the term scientist could pose a narrow view of what it means to engage in science from a student's perspective because it implies that an individual is actively engaging in science outside of the classroom. Therefore, studying a research scientist's community of practice (e.g., using the word scientist rather than science person) when asking students questions about their science identity could be problematic. The term scientist could be irrelevant to college students depending on their experience with science outside of school, especially in the beginning of their undergraduate career 
when students may have no research experience. Measures of research scientist identity have been used to study the impacts of science support experiences such as research and mentoring that occur outside of the classroom (Chemers, et al., 2011; Robnett, et al., 2015; Estrada, et al., 2018), but they may not be appropriate for identity changes within the classroom. One measure of science identity was designed to specifically address a single intervention within the classroom and is therefore useful for the assessment of that specific intervention (Childers and Jones, 2017). While there are several identity measures, many of them lack the appropriate context or are not designed to specifically address chemistry identity. While a specific measure of chemistry identity has not been developed, the physics identity measure provides starting point for its development.

\section{History of the physics identity measure}

Hazari et al., (2010) operationalized and modified Carlone \& Johnson's (2007) science identity theory (Figure 1A) and developed a theoretical framework for physics identity for the purpose of building a physics identity measure. In the physics identity framework (Hazari, et al., 2010), social-cognitive career theory (SCCT) (Lent, et al., 1994), which is heavily based on Bandura's social cognitive theory (SCT) (Bandura and National Inst of Mental Health, 1986), was used to ground the overall physics identity theory. SCCT "emphasizes the means by which individuals exercise personal agency in the career development process, as well as extra-personal factors that enhance or constrain agency" (Lent, et al., 1994). The proposed model (Figure 1B) included the constructs of performance (belief in ability to perform required physics tasks), competence (belief in ability to understand physics content), recognition by others (recognition by others as being a good physics student), and interest (desire/curiosity to think about and understand physics). Three distinct modifications were made to the Carlone \& Johnson science identity theory to develop the physics identity theory. First, interest was not originally included in the Carlone \& Johnson science identity theory because it was based on women who were already on an established path to become scientists and therefore their interest did not need support (Carlone and Johnson, 2007). However, Carlone \& Johnson did note that interest was an important factor for identity formation. The population within the Hazari et al. (2010) study included students who were non-physics majors or earlier in their physics academic career, where interest may not be stable and therefore would 
be valuable to measure. Based on this, and evidence that interest has a large impact on career choice and therefore who or what a student wants to be (Lent, et al., 1994), Hazari et al. (2010) decided to include the construct of interest within their physics identity framework. Second, performance and competence were re-defined to reflect confidence in ability (similar to self-efficacy) rather than purely ability. The third modification between the theories was the conceptualization of recognition. Within the Carlone \& Johnson identity theory, self-recognition was combined with recognition by others, whereas Hazari et al. (2010) viewed self-recognition as a core feature that could be influenced by whether an individual is recognized by others. Therefore, self-recognition was theorized as a separate holistic identity variable consisting of a single item that asked "Do you see yourself as a physics person?" (Shanahan, 2009; Potvin and Hazari, 2013). Items based on these constructs were tested and, after exploratory factor analysis (EFA), a revised version of the framework that consisted of performance/competence as a single construct, recognition by others, an identity variable (i.e., self-recognition) and interest (Figure 1C). The physics identity measure, containing items aligned to the constructs of performance/competence, recognition, and interest along with the identity variable, has been modified for use in other disciplines and items within the measure have gone through multiple iterations and psychometric testing (Cass, et al., 2011; Godwin, et al., 2013; Cheng, et al., 2018; Verdín, et al., 2018). 
SCIENCE IDENTITY

(Carlone and Johnson 2007)
PHYSICS IDENTITY

(Hazari et. al., 2010)
B)

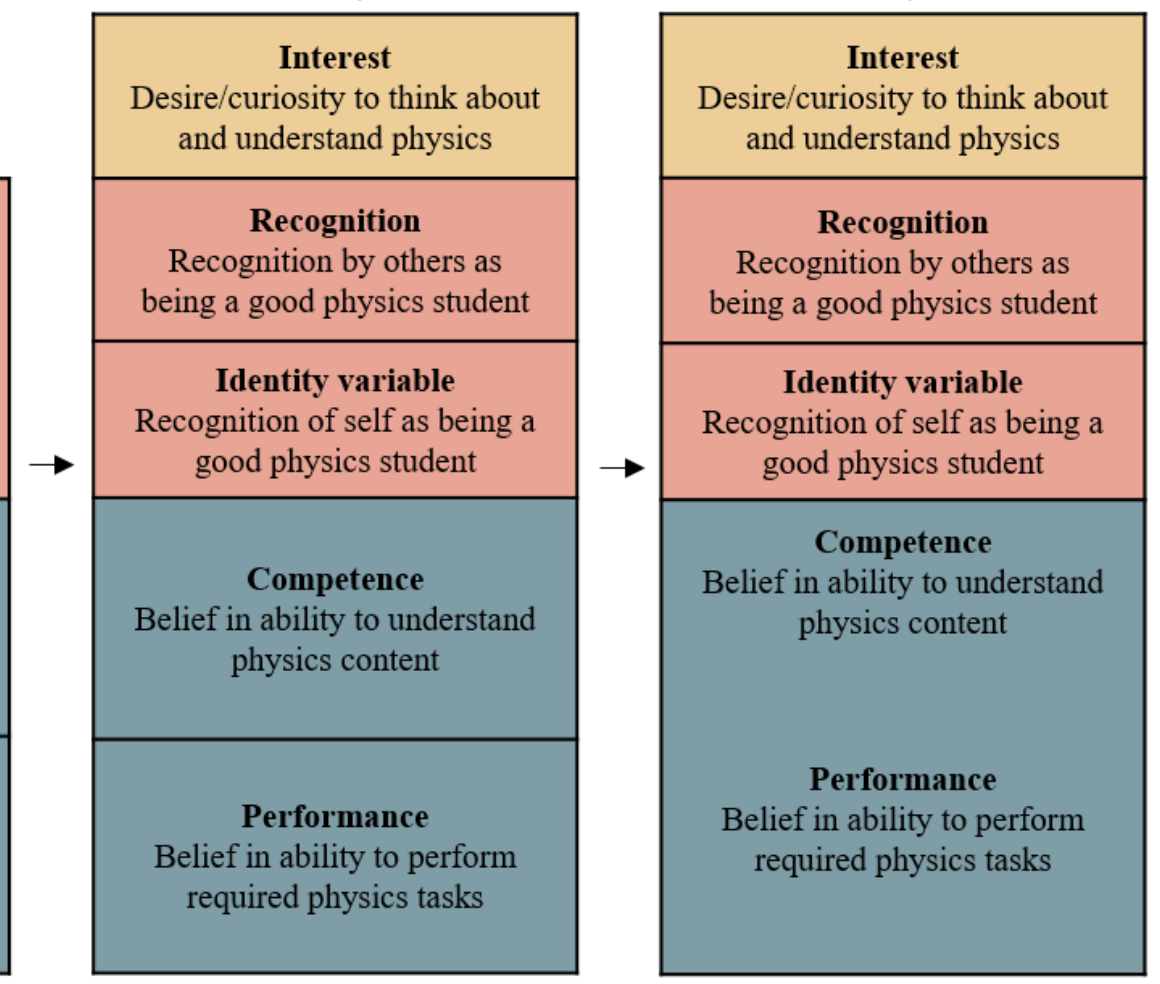

Figure 1. The theoretical frameworks for A) science identity, B) physics identity, and C) physics identity after modification.

\section{Initial physics identity items}

While Hazari et al., (2010) described the grounding of their physics identity theoretical framework, the process for development of the sub-construct items is somewhat unclear. The first physics identity items (associated with the constructs described in Figure 1B) were part of a large national survey from the Persistence Research in Science and Engineering (PRiSE) Project. The PRiSE survey set out to explore factors from high school that influence persistence of females within STEM and was developed using three methods: a literature review of constructs that affect persistence, open-ended responses from 259 secondary science teachers and 153 scientists on what they believe influences persistence in college, and extraction of items from a previously used national survey (Factors Influencing College Success-FICSS). In total, the PRiSE survey was comprised of 50 items across 6 sections, requiring more than 250 individual responses from students. The original physics identity survey was compiled from a range of PRiSE items. However, few details were provided regarding why the items were chosen or how they were assigned to each sub-construct of identity through the theoretical framework of

\section{SCCT.}




\section{Performance/Competence}

Performance was measured using five PRiSE items about middle school and high school grades along with SAT scores. It is of note here that the construct of performance was measured using student ability in the form of past grades, whereas the definition of performance within the physics identity framework described performance as belief in ability. Competence was measured using two PRiSE items about students' perceived confidence in middle school math and science. Within SCCT, the construct of performance is theorized to influence one's selfefficacy and therefore career goals and choices while the construct of competence is not specifically mentioned.

\section{Interest}

Nineteen PRiSE items were used to measure the construct of interest. These items reflected interest in specific tasks associated with three domains: physics interest (e.g., mechanics and electromagnetism), science interest (e.g., understanding natural phenomena and using mathematics), and science activity (e.g., participation in science groups/clubs/camps and science/math competitions). Within SCCT, interest is defined as “...likes, dislikes, and indifferences regarding career-relevant activities and occupations" (Lent, et al., 1994). The interest items on the PRiSE survey were not explicitly tied to career-relevant activities or occupations.

\section{Recognition}

Items measuring recognition on the PRiSE survey included items where students rated whether certain groups (i.e., their science teacher or their parents/relatives/friends) saw them as a physics person. These two items of recognition were retained for the physics survey, however, the definition of recognition within the physics identity framework pertains to whether a student is recognized as a good "physics student". These wording differences could conflict based on students" definitions of "physics person". Recognition is not specifically mentioned in SCCT but does align well with the verbal persuasion source of self-efficacy defined within SCT (Bandura and National Inst of Mental Health, 1986), although this alignment is not mentioned by Hazari et al. (2010).

\section{Further modifications}

Subsequent publications have utilized the Hazari et al. (2010) framework (Figure 1C) with item modifications (Godwin, et al., 2013; Godwin, et al., 2016; Cheng, et al., 2018). However, little to no explanation of the decisions to add or delete items or change item wordings has been described. For example, more recent versions contain broadly worded interest items such as "I am interested in learning more about the subject [physics]" (Godwin, et al., 2013) and "I enjoy learning about physics" (Cheng, et al., 2018), as compared to the 
original items that described interest with regard to specific content within physics. While these items were developed based on performance, competence, interest, and recognition proposed by Hazari et al. (2010), the process of development to ensure that items reflected each sub-construct remains unclear. Due to the lack of clear theoretical connections to the sub-constructs of identity and the items developed to measure them, it is worth exploring the sub-constructs and their connection to established affective constructs within the literature.

\section{Purpose and rationale for the study}

While psychometrics, such as EFA, are crucial to validity, it is equally as important to show the development of measures based on an established theory (Furr and Bacharach, 2008; Kline, 2016). While items designed to reflect performance/competence, interest, and recognition have been used in prior studies of student identity (Godwin, et al., 2013; Cribbs, et al., 2015; Cheng, et al., 2018; Verdín, et al., 2018) and shown evidence of valid data through psychometrics, there has been little evidence to support the theoretical backing of the items used to measure these sub-constructs of the physics identity framework. Providing evidence for the alignment between items and the construct being measured is crucial to content validity (Furr and Bacharach, 2008). Therefore, this study used semi-structured interviews to provide further evidence of content validity through two related aims. The first aim of this study was to explore the constructs of performance/competence, recognition, and interest, within the physics identity framework, through student responses to previously used items. The second aim was to build upon the physics identity framework by exploring the connections between the sub-constructs of identity and theoretically grounded affective constructs. Rooting the sub-constructs of identity within a defined theoretical framework is the primary step in our development of measures of identity for use within chemistry education.

The aims of this project will be carried out through addressing the following research questions:

1) What themes arise when students are asked questions reflecting performance/competence, recognition, and interest, pertaining to science or chemistry, as described by the physics identity framework?

2) To what extent do reported themes align with proposed and other affective constructs? 


\section{Methods}

\section{Participants}

After obtaining institutional review board (IRB) approval for the study, the sample consisted of students in undergraduate chemistry courses at Portland State University (PSU). To sample a range of student levels (e.g., by major and year in degree), the selected courses included an off-sequence general chemistry course, two sections of an organic chemistry course, and a biochemistry course for nonbiochemistry majors. Student enrollment for the four courses were 233, 162, 131, and 235, respectively. A final question on a two-question recruitment survey asked students if they were willing to participate in a follow-up interview. Students who responded positively to the question were recruited and randomly selected for interviews. To capture a range of responses, quota sampling was used (Tourangeau and Yan, 2012), where an equal number of participants per specified responses were selected. Responses to the two items, "I see myself as a science person" and "I see myself as a chemistry person" from the related survey, were used to select participants. Students who agreed to participate in an interview were separated into three groups: 1) those who agreed with both statements (by selecting "agree" or "strongly agree" on the Likert scale for both items), 2) those who did not agree with both statements (by selecting "neutral", "disagree", or "strongly disagree" for both items), and 3) those who had selected "neutral", "disagree", or "strongly disagree" for the chemistry identity item and "agree" or "strongly agree" for the science identity item. Of note, there were no students who volunteered for an interview who had selected "neutral", "disagree", or "strongly disagree" for the science identity item and "agree" or "strongly agree" for the chemistry identity item. One student from each of the three groups was then randomly selected for an interview. This was repeated until there was one student per group per course type, for a total of nine interviews.

\section{Data collection}

A semi-structured interview format was used to investigate student responses to questions designed to target performance/competence, recognition, and interest, as outlined in the physics identity framework. First, participants were asked two open-ended questions: What makes someone a science person? and What makes someone a chemistry person? Next, items from an instrument designed from the physics 
identity theory (Godwin, et al., 2013) were used. Items describing each sub-construct of physics identity have gone through multiple iterations (Godwin, et al., 2013; Cribbs, et al., 2015; Cheng, et al., 2018; Verdín, et al., 2018). Therefore, only the items that have been the most consistently used within the literature were utilized in this study. These items were modified for the purpose of being posed as openended questions to students. For example, the item "I see myself as a science person" was modified to "Do you see yourself as a science person?" After asking the science worded version of the question and any relevant follow-up questions, the chemistry worded version of the question was asked, i.e., "Do you see yourself as a chemistry person?" These open-ended questions formed the semi-structured interview protocol (included in the Appendix).

\section{Analysis}

Interviews were transcribed using a professional transcription service. The transcribed interviews were then analyzed using a thematic analysis framework (Braun, et al., 2019) with the software MAXQDA (Version 18.2.0). Thematic analysis is a method used to describe themes (patterns of meaning) within the data. There are many ways to utilize thematic analysis, but regardless of how it is utilized, it is crucial for researchers to report the way the method was used so that the assumptions of the method are clear (Braun and Clarke, 2006). The thematic analysis was performed through an essentialist lens (Braun and Clarke, 2006), which assumes the responses of participants directly reflect their experiences. To obtain a holistic picture of participant responses when asked about performance/competence, recognition, and interest, the thematic analysis was used as an inductive method of analysis as compared to a deductive analysis method, where a priori codes are developed. The process of data analysis was carried out both independently and collaboratively by the first author and an undergraduate researcher trained in chemistry education. The reflexive thematic analysis used in this study followed five steps as described by Braun and Clarke (2019): 1) familiarization, 2) generating codes, 3) constructing themes, 4) revising themes, and 5) defining themes. First, two of the nine transcripts were read independently and multiple times to gain familiarity with the data. During these reads, each researcher recorded notes on patterns within the two transcripts. The second step contained multiple sub-steps. The two researchers came together to record all identified patterns from their notes 
and combined similar patterns when necessary. A codebook with codes and definitions was then created based on the final list of patterns. This codebook was then used by the researchers to independently code two additional transcripts and notes of new codes were recorded. Once again, the researchers came together to refine codes and edit the codebook. This process was repeated one more time with two additional transcripts until a final codebook was established. Reflexive thematic analysis does not use strict measures of inter-rater reliability. Coding is considered an iterative process where codes are continually developed throughout analysis (Braun, et al., 2019). In this case, the codebook was considered complete when the two researchers reached a consensus that there were no more unique codes. The final codebook was used by the researchers to independently code two new transcripts to confirm that no new codes were discovered. Once the final codebook was confirmed, the last transcript was coded and all transcripts were re-coded to consensus. To explore the prevalence of codes within specific portions of the interviews, transcripts were divided into four sections according to Table 1.

Table 1. Division of interviews into sections by grouped items. The word [science] was replaced with chemistry for the chemistry-worded version of each question.

\begin{tabular}{ll}
\hline Section & Questions included \\
\hline Attributes and Self-Recognition & What do you think makes someone a [science] person? \\
& Do you see yourself as a [science] person? \\
\hline Recognition by Others & Do your friends see you as a [science] person? \\
& Do your peers see you as a [science] person? \\
& Do people who are important to you see you as a [science] person? \\
& Have you had specific experiences that you can recall where you \\
& feel like you've been recognized as a [science] person? \\
\hline Performance/Competence & How confident are you that you can understand [science] in class? \\
& How confident are you that you can understand [science] outside of \\
& class? \\
& Do you do well on exams in [science]? \\
& Do others as you for help in [science]? \\
& Have you overcome any setbacks in [science]? \\
\hline Interest & Are you interested in learning more about [science]? \\
& Do you enjoy learning [science]? \\
& Do you find fulfillment in doing [science]? \\
\hline
\end{tabular}

After all transcripts were coded, the final three steps of analysis consisted of evaluating the generated codes for themes, revising, and defining codes. Codes were rearranged into groups multiple times until the first author decided on a final set of groupings that resulted in themes. The themes were then defined by the first author, reviewed by the second author, and subsequently discussed with secondary 
researchers. The final themes were used to explore connections of the sub-constructs of

performance/competence, recognition, and interest with established affective constructs.

\section{Results and Discussion}

Nine students participated in semi-structured interviews that included questions about

performance/competence, recognition, and interest and overall science and chemistry identity. Table 2

shows demographic information for each participant and the responses to the items used for interview

selection. Pseudonyms were used to protect each participant's identity. While the participating sample is

almost entirely female and Caucasian, the participant selection for interviews was randomized among

those who volunteered to take place in an interview and met our quota sampling criteria. In total,

seventeen females and six males were randomly recruited from the pool of volunteers. Of those recruited,

nine females and five males either declined or did not respond to scheduling an interview.

Table 2. Pseudonyms and demographics for interview participants.

\begin{tabular}{|c|c|c|c|c|c|c|}
\hline Name & Course* & $\begin{array}{l}\text { Gender } \\
\text { Identity }\end{array}$ & Race** & University Status*** & $\begin{array}{l}\text { I see myself as a } \\
\text { science person }\end{array}$ & $\begin{array}{l}\text { I see myself as a } \\
\text { chemistry person }\end{array}$ \\
\hline Max & $\mathrm{GC}$ & Female & Caucasian & Undergrad & Strongly agree & Strongly agree \\
\hline Nancy & $\mathrm{OC}$ & Female & Polynesian & Undergrad & Agree & Agree \\
\hline Karen & $\mathrm{BC}$ & Female & Caucasian & Transfer/Undergrad & Strongly agree & Agree \\
\hline Barb & $\mathrm{GC}$ & Female & Caucasian & Undergrad & Agree & Disagree \\
\hline Joyce & $\mathrm{OC}$ & Female & $\begin{array}{l}\text { Caucasian } \\
\text { /Asian }\end{array}$ & Undergrad & Agree & Disagree \\
\hline Steve & $\mathrm{BC}$ & Male & Caucasian & Undergrad & Strongly agree & Strongly disagree \\
\hline Elle & $\mathrm{GC}$ & Female & Caucasian & Undergrad & Strongly disagree & Strongly disagree \\
\hline Erica & $\mathrm{OC}$ & Female & Slavic & Post-bac & Disagree & Disagree \\
\hline Robin & $\mathrm{BC}$ & Female & Caucasian & Post-bac & Disagree & Disagree \\
\hline
\end{tabular}

\section{Identified codes}

Twelve codes were determined throughout the nine semi-structured interviews. The codebook was created using six of the nine transcripts. When using the codebook to analyze the final three transcripts, no novel codes were discovered, which provided evidence of data saturation (Guest, et al., 2006). Codes, their definitions, and examples are shown in Table 3.

Table 3. Codes, their definitions, and examples of codes within the text.

\begin{tabular}{ll}
\hline Code Definition & Example of Segment from Text
\end{tabular}




\begin{tabular}{ll}
\hline Feelings & $\begin{array}{l}\text { Positive or negative feelings associated with science “...I love biology...” } \\
\text { or chemistry (e.g., enjoy, interesting, fun, boring, } \\
\text { overwhelming). }\end{array}$
\end{tabular}

\begin{tabular}{ll}
\hline Real-world & $\begin{array}{l}\text { Science or chemistry in conjunction with its } \\
\text { application of } \\
\text { applications to the real-world/everyday life or to } \\
\text { science or }\end{array}$ \\
chemistry & $\begin{array}{l}\text { applications (i.e., using hands to perform science). } \\
\text { Science or chemistry as a form of altruism. Science } \\
\text { or chemistry as a way to create new technologies } \\
\text { (innovations) and solve problems. }\end{array}$
\end{tabular}

"I do enjoy learning some of the concepts and some of the real-world...aspect of it."

\begin{tabular}{|c|c|}
\hline Goals & $\begin{aligned} \text { Science or chemistry is used as a means to an end. } & \text { "I wanna go to medical school so that's stuff I } \\
& \text { would like to learn more about." }\end{aligned}$ \\
\hline $\begin{array}{l}\text { Science or } \\
\text { chemistry as an } \\
\text { epistemology }\end{array}$ & $\begin{array}{l}\text { Science or chemistry used as a way of obtaining } \\
\text { knowledge about the world. }\end{array}$ \\
\hline $\begin{array}{l}\text { Knowledge of } \\
\text { science or } \\
\text { chemistry }\end{array}$ & $\begin{array}{l}\text { Possessing some foundational knowledge of science "I think they have to at least have some sort of } \\
\text { or chemistry. Understanding of science or chemistry knowledge of science...to make them a science } \\
\text { concepts. } \\
\text { person." }\end{array}$ \\
\hline $\begin{array}{l}\text { Performance in } \\
\text { school }\end{array}$ & $\begin{array}{l}\text { "I was not expecting to do very well in the tests } \\
\text { but I ended up getting a B on the final, and I was } \\
\text { really surprised." }\end{array}$ \\
\hline $\begin{array}{l}\text { Encouragement/ } \\
\text { Discouragement }\end{array}$ & $\begin{array}{ll}\text { When participant is encouraged/affirmed OR } & \text { "...my parents are always encouraging and } \\
\text { discouraged by people in their life including family, supportive of me in science areas and ever since I } \\
\text { teachers, friends, peers. Also includes feeling } & \text { was young" } \\
\text { encouraged by receiving awards. } & \end{array}$ \\
\hline
\end{tabular}

\begin{tabular}{lll}
\hline $\begin{array}{l}\text { Science or } \\
\text { chemistry in } \\
\text { conversation }\end{array}$ & $\begin{array}{l}\text { Science or chemistry is discussed in various ways } \\
\text { with others such as debating, using scientific jargon, discuss--go on hypothetical voyages of things } \\
\text { or discussing science or chemistry in general. } \\
\text { about science." }\end{array}$ \\
\hline $\begin{array}{l}\text { Explaining } \\
\text { science or } \\
\text { chemistry to } \\
\text { others }\end{array}$ & $\begin{array}{l}\text { The participant's competency in science or } \\
\text { chemistry is expressed to others through explaining }\end{array}$ & $\begin{array}{l}\text { "I'm an anatomy person, so they'll ask me certain } \\
\text { things about the body or whatever. And so when } \\
\text { it comes to subjects of science that I know, then } \\
\text { they'll ask me questions about that. And then } \\
\text { they'll know that I know the answers and stuff like } \\
\text { that." }\end{array}$
\end{tabular}

Comparison to Referencing their place in science or chemistry "My boyfriend really enjoys chemistry and others based on others. biology, and I'm like, 'how?' I don't understand.”

\begin{tabular}{lll}
\hline $\begin{array}{l}\text { Intuition for } \\
\text { understanding } \\
\text { science or } \\
\text { chemistry }\end{array}$ & $\begin{array}{l}\text { Science or chemistry comes easily or naturally. } \\
\text { Science or chemistry takes a certain type of thinking } \\
\text { (e.g., strong visual/conceptual perception of abstract } \\
\text { concepts). }\end{array}$ & \\
\hline Determination & $\begin{array}{l}\text { Persisting through challenges in science or } \\
\text { chemistry. }\end{array}$ & $\begin{array}{l}\text { "And I think at first it was pretty challenging for } \\
\text { me and just trying to think about all the new kind } \\
\text { of concepts but I was able to ask for help and } \\
\text { work through it and I was able to do it" }\end{array}$ \\
& & \\
& &
\end{tabular}


It is important to note that codes were assigned to any portion of the text that contained the description of the code throughout the entire interview, not simply in the response connected to a subset of questions. The prevalence of each code was determined for each of the four sections in the interviews as described in Table 1: Attributes and Self-Recognition, Recognition by Others, Performance/Competence, and Interest. In addition to the four sections, the responses to science and chemistry worded questions were combined when analyzed for the prevalence of codes. For example, the responses from "Do your friends recognize you as a science person" and "Do your friends recognize you as a chemistry person?" If a code was present within both responses, it was only counted one time. This was done because students sometimes conflated science and chemistry when asked specifically about science. Therefore, chemistry follow up questions were not always asked. The number of participants that mentioned each code within each section is shown in Table 4. Portions of text within responses could be coded with more than one code, sometimes resulting in multiple codes per response per participant. The constructs of performance/competence, recognition, and interest have been theorized to correlate, therefore it was not a concern that single codes appeared in multiple sections of the interview. Therefore, to clarify how many unique interviews contained the code, an "overall" column was added to Table 4. For example, in the first row of the table, the code "Goals" was applied to the discussions of six interview participants. For these participants, the "Goals" code was differentially applied within each of the four sections of the interview. It can be seen that while each of these participants discussed "Goals" during the Interest section of their interview, fewer discussed this aspect within the other sections, with only one discussing "Goals" within their Performance/Competence section. 
Table 4. The number of interviews and sections that contained each individual code.

\begin{tabular}{lccccc}
\hline Codes & $\begin{array}{c}\text { Number of } \\
\text { Interviews }\end{array}$ & $\begin{array}{c}\text { Attributes } \\
\text { and Self- } \\
\text { Recognition }\end{array}$ & $\begin{array}{c}\text { Interview Sections } \\
\text { Recognition } \\
\text { by Others }\end{array}$ & $\begin{array}{c}\text { Performance/ } \\
\text { Competence }\end{array}$ & Interest \\
\hline Goals & 6 & 4 & 5 & 1 & 6 \\
Feelings & 9 & 9 & 7 & N/A* & 8 \\
Real-world application & 9 & 7 & 4 & 6 & 9 \\
Science as an epistemology & 7 & 7 & 2 & N/A & 5 \\
Knowledge of science or chemistry & 6 & 4 & 4 & 5 & 4 \\
Performance in school & 9 & 6 & 5 & 9 & 1 \\
Encouragement & 6 & 1 & 5 & 1 & N/A \\
Science or chemistry in conversation & 8 & 1 & 8 & 2 & 1 \\
Trusted as a science or chemistry source & 9 & N/A & 6 & 6 & N/A \\
Comparison of self with others & 8 & 2 & 7 & 3 & N/A \\
Intuition for understanding & 9 & 8 & 1 & 2 & N/A \\
Determination & 6 & 4 & 4 & 5 & 4 \\
\hline
\end{tabular}

*N/A indicates that the code did not appear in this section within any interviews.

\section{Emergent themes}

Codes were combined to create overarching themes that were discussed when students were asked about performance/competence, recognition, interest, and overall science and chemistry identity. Four themes were determined from the twelve codes present within the semi-structured interviews. Themes, the codes contained within each theme, and an overall description of the themes are contained in Table 5. Each theme and how it was used within the interviews is described below.

Table 5. Themes, codes contained within each theme, and a description of each theme that are present throughout the interviews.

\begin{tabular}{lll}
\hline $\begin{array}{l}\text { Theme } \\
\begin{array}{l}\text { Interest in science or chemistry } \\
\text { is based on feelings or values } \\
\text { and occurs in stages. }\end{array}\end{array}$ & $\begin{array}{l}\text { Feelings, real-world application, } \\
\text { goals, science as an epistemology }\end{array}$ & $\begin{array}{l}\text { Description } \\
\text { Interest in science or chemistry was } \\
\text { described using feelings or interest tied to } \\
\text { values such as the real-world applications } \\
\text { of science or chemistry, goals that depend } \\
\text { on science or chemistry, or science and } \\
\text { chemistry as a tool to solve problems. } \\
\text { Amount of interest in science or chemistry } \\
\text { varied between students. }\end{array}$ \\
\hline $\begin{array}{l}\text { Educational experiences } \\
\text { contribute to student science or } \\
\text { chemistry identity. }\end{array}$ & $\begin{array}{l}\text { Knowledge of science or chemistry, } \\
\text { performance in school }\end{array}$ & $\begin{array}{l}\text { Participation in science or chemistry was } \\
\text { described using examples from } \\
\text { educational experiences. }\end{array}$ \\
\hline $\begin{array}{l}\text { Students gain information about } \\
\text { identity through interactions } \\
\text { with others. }\end{array}$ & $\begin{array}{l}\text { Encouragement, science or } \\
\text { chemistry in conversation, trusted as } \\
\text { a science or chemistry source, } \\
\text { comparison of self with others }\end{array}$ & $\begin{array}{l}\text { The relation of a participant to science or } \\
\text { chemistry was discussed in terms of } \\
\text { gaining information about oneself through } \\
\text { interacting with people in their lives. }\end{array}$ \\
\hline $\begin{array}{l}\text { Participation in science or } \\
\text { chemistry takes a certain type } \\
\text { of person. }\end{array}$ & $\begin{array}{l}\text { Intuition for science or chemistry, } \\
\text { determination }\end{array}$ & $\begin{array}{l}\text { Certain types of people are more suited } \\
\text { toward participating in science or } \\
\text { chemistry based on certain traits. }\end{array}$ \\
\hline
\end{tabular}




\section{Theme 1: Interest in science or chemistry is based on feelings or values and occurs in stages}

Interest is based on feelings and values.

Students frequently described interest in science or chemistry based on their feelings or values throughout the interviews. Representative student quotes can be found within Table 6 . All students referenced feelings toward science throughout the Attributes and Self-Recognition section of the interviews. For example, Robin mentioned excitement when describing the attributes of a science person. Erica used words such as exciting, entertaining, and fun to describe how her professor sees chemistry and was the reason she saw him as a chemistry person as compared to herself. Within the Recognition section, when asked if others see them as a science or chemistry person, some students, such as Max and Joyce, thought others knew about their interest (or disinterest) in the subject and was a form of being recognized (or not recognized) as a science or chemistry person. Additionally, these feeling-related words were used by students to describe reasons they did or did not recognize themselves as science or chemistry people. Examples come from Steve and Elle within the Attributes and Self-Recognition section, as they use words such as psyched, love, and enjoy when describing their feelings toward chemistry.

In addition to feelings, students frequently mentioned real-world applications, goals, or using science as a tool to obtain knowledge when responding to questions. These types of references are reflective of their interest related to values, i.e., they are interested in science or chemistry because it is valuable, or important to them (Schiefele, 1991). For example, Robin and Barb described their career goals within the medical field as drivers of their interest in science, and Erica described real-world application in relation to her interest in chemistry. The discussion of real-world applications of science provided a link between the value of science pertaining to Barb's interest and how this affected her confidence. Within the Attributes and Self-Recognition portion of the interview, Barb described being interested in science because of the real-world application of the subject and later, in the Performance/Competence section, described how real-world applications aided in her confidence of biology.

Table 6. Student quotes pertaining to feeling- and value-related interest.

\begin{tabular}{lll}
\hline Interest Component & Student & Quote \\
\hline Feeling & Robin & $\begin{array}{l}\text { "I think if people are really excited about science that would make them kind } \\
\text { of a science person." }\end{array}$ \\
\cline { 2 - 3 } & Erica & "Yeah, Idon't see myself as a chemistry person. I had a good professor who I \\
& can totally...he's a chemistry person. He gets really excited when he talks \\
& about it, and he finds it entertaining and fun."
\end{tabular}




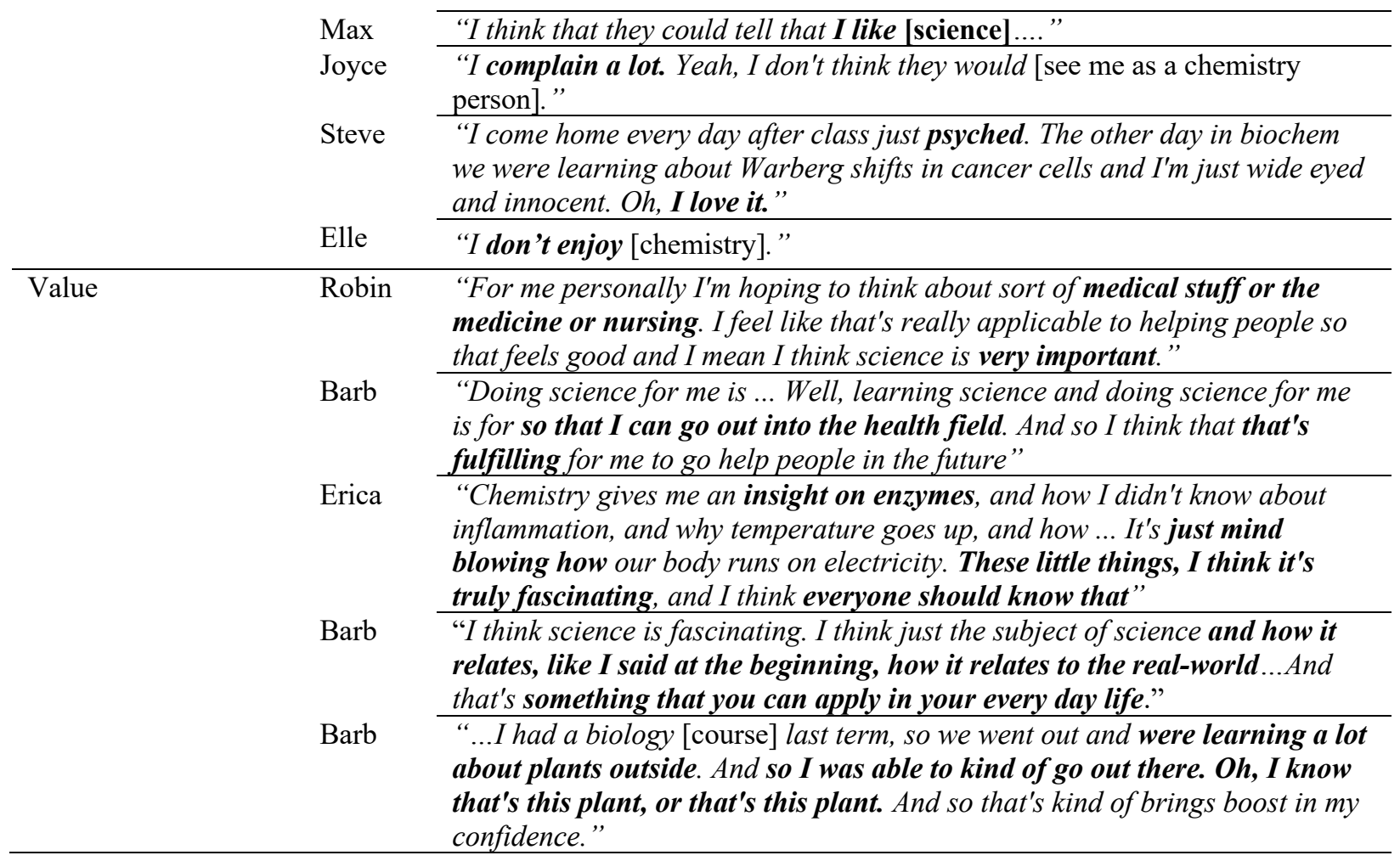

Interest occurs in stages

In addition to discussing feelings and values when describing interest in science or chemistry, students seemed to be in varying stages of interest (Hidi and Renninger, 2006). Representative student quotes are available in Table 7. For example, Barb described that she did not always enjoy chemistry, which suggested her interest was in the early stages of formation. Similarly, Steve explained his growing interest in chemistry after realizing the practical applications. After this recognition, Steve was able to engage more with the material in his biochemistry course. Nancy and Max described situations where their interest is heightened after being in the classroom, which suggested their interest was continuing to grow based on classroom material. The Table 7 examples from Barb, Steve, Nancy, and Max, suggested that student interest is heightened after learning something in the classroom and in some cases, they are re-engaging with the material themselves, such as discussing it with others.

While there were examples of students describing their growing interest, some students described having more of a solidified interest pertaining to science or chemistry. For example, when Robin was asked what makes her interested in science, she suggested that science has been integrated into the way she thinks and therefore she re-engages with science often. This supported a more concrete and stable 
form of interest. While the responses by students were not clear enough to confidently say what stages of interest development students were in, there was evidence that students experienced varying amounts of interest in science and chemistry.

Table 7. Student quotes pertaining to varying stages of interest.

\begin{tabular}{|c|c|c|}
\hline Interest Formation Stage & Student & Quote \\
\hline \multirow[t]{2}{*}{ Early } & Barb & $\begin{array}{l}\text { "Sometimes, I do [enjoy chemistry]. I enjoy lab. I enjoy } \\
\text { learning some of that stuff, and I enjoy learning ... I do enjoy } \\
\text { learning some of the concepts and some of the real-world, } \\
\text { like I said, the real-world aspect of it." }\end{array}$ \\
\hline & Steve & $\begin{array}{l}\text { "And then all of a sudden you're like, "Oh my gosh! This is } \\
\text { cool!" Especially with biochem. ... I didn't realize the } \\
\text { practical application of chemistry. And now you have whole } \\
\text { new world of appreciation for it." }\end{array}$ \\
\hline \multirow[t]{2}{*}{ Mid } & Nancy & $\begin{array}{l}\text { "That I can learn something and then I can go out...and } \\
\text { relate it and tell people my nerdy answers." }\end{array}$ \\
\hline & Max & $\begin{array}{l}\text { "Like specifically with psychology or biology and you learn } \\
\text { something and then you're like so that's why that happens." }\end{array}$ \\
\hline Late & Robin & $\begin{array}{l}\text { "I mean, it's a way to understand the world and...I think } \\
\text { when I can apply it to sort of real life, it's really, really } \\
\text { fascinating. And I love to kind of know about how things } \\
\text { work and I think it's also a way to help people and so yeah." }\end{array}$ \\
\hline
\end{tabular}

\section{Theoretical frameworks surrounding Theme 1}

Students were interested in science based on their feelings and values. In addition to feelings and values, students described varying degrees of interest. As outlined by the physics identity framework, interest has been proposed as a construct that is a part of domain-specific identity formation. However, the description was not specifically aligned within a theory of interest. Based on the responses of students when discussing interest, the construct of interest as described by the physics identity framework aligned well with the theories that describe feeling- and value-related interest (Schiefele, 1991) and the fourphases of interest (Renninger and Hidi, 2011).

Feeling- and value-related interest

Schiefele (1991) has proposed that there are two components to interest: value-related and feelingrelated. Value-related interest refers to the significance an individual has to a particular subject, whereas feeling-related interest refers to the positive feeling one relates to a particular subject. Schiefele (1991) states, "Although these two components correlate highly with one another, it seems justified to distinguish between them (p. 303)." Within the Interest section of the interviews, students discussed the construct of interest through both feelings and values. These responses directly aligned with feeling- and value-related components of interest. Words describing feelings such as fascinating, cool, and interesting 
were used when students were asked to describe their interest in science or chemistry. These feelingcentered words were commonly followed up with statements describing students' values such as the application of science or chemistry to the real-world and the goals students will achieve through science or chemistry.

\section{The four-phases of interest}

Although the term "interest" is often used by researchers, it is not always well defined or specifically placed within a theoretical framework (Schiefele, 1991; Renninger and Hidi, 2011). Interest can be conceptualized in many ways such as development (Hidi and Renninger, 2006; Krapp, 2007), emotion (Silvia, 2005; Ainley, 2007), and environment (Sansone, et al., 2011). While there are multiple conceptualizations of overall interest, there are two general categories of interest within the current psychological literature: situational interest and individual interest. Situational interest is influenced by the environment an individual is in at the time, such as a classroom, and may or may not last over time. Individual (or personal) interest refers to the type of long-lasting interest that is less influenced by the environment. This type of interest forms over time and focuses on an individual's inner development of interest.

The four-phase model views interest from a development standpoint and describes four sequential and cumulative phases in interest development involving situational and individual interest: triggering situational interest, maintained situational interest, emerging individual interest, and well-developed individual interest (Hidi and Renninger, 2006). Triggering situational interest is the first phase of interest development. An individual's interest is peaked when something within their environment triggers their interest, such as when Steve discussed engaging with chemistry after realizing the real-world applications. This engagement could then lead to the second phase of interest development; maintained situational interest. In the maintained situational interest phase, a student may become interested in course content based on a previous trigger and begin to re-engage with material. Within this phase, interest is sustained based on meaningfulness of tasks, such as Nancy and Max when they described applying their knowledge to something new. The third phase is emerging individual interest, which is categorized by stored knowledge, values, and positive feelings. Within this phase, interest is mostly self-generated. For 
example, a student may begin to increasingly value their interaction with the course material based on previous engagement and will continue to re-engage with the material. This was illustrated by Robin, when she described integrating science into her "real life" to understand how things work. It is also possible that Robin was in the final phase of interest development; well-developed individual interest. This phase is categorized by more stored knowledge, value, and positive feelings than emerging individual interest. Similar to emerging individual interest, well-developed individual interest is mostly self-generated. An individual will seek out extra opportunities to re-engage with the subject even if faced with setbacks within this phase. For example, a student may choose to take a non-required course despite a non-ideal grade in a previous chemistry course.

Based on the four-phase model of interest, the appropriate measure of interest depends on the population under study. Within the Carlone \& Johnson (2007) research, interest was not studied because the participating women were in their late undergraduate years and early career and it was assumed that their interest in science was established. This established phase of interest aligns with the emerging or well-developed phases of individual interest. Hazari et al. (2010) studied a population that was earlier within their undergraduate career and not solely STEM majors. Triggered or maintained situational interest may have aligned more appropriately with this population, as the particular students may have been more prone to changes in interest based on their classroom environments. Designing a measure to target specific phases of interest can provide more detailed information on what phase of interest is the most impactful on identity formation. Situational interest is the most malleable phase of interest and could be an important construct to target when studying identity formation within classroom environments.

\section{Theme 2: Educational experiences contribute to student science or chemistry identity.}

Students made it clear that educational experiences pertaining to science and chemistry were a crucial component of science and chemistry identity. Representative student quotes can be found within Table 8 . Within the Attributes and Self-Recognition section of the interview, Elle described a chemistry person as someone who does well in class, Steve described a chemistry person as being careful in the course laboratory, and Max described herself as a science person because of success in the classroom. These statements provided evidence that students were drawing on experiences within the classroom or 
laboratory to describe science and chemistry people rather than experiences with science and chemistry outside of the classroom.

Students continued to draw on educational experiences to relate to science and chemistry within the Performance/Competence section. For example, when asked generally about setbacks in science or chemistry, students frequently mentioned setbacks in the classroom such as poor grades or repeating a course. Examples come from Erica, who had to overcome poor exam grades, and Barb, who repeated courses because of poor course grades. When asked about confidence in science or chemistry, students mentioned their performance in school or knowledge of science or chemistry content as the basis of their confidence. For example, Karen described doing well on an exam for the basis of her confidence. Educational experiences in reference to identity were also present within the Recognition section. Erica and Karen both described their experiences performing well within the subject as a way that others recognized them as science or chemistry people.

Throughout the interviews, students described educational experiences as a source of science or chemistry identity. This theme aligned with Carlone \& Johnson's original definitions of performance and competence (Figure 1A) because students were directly describing their competency and performance in their education pertaining to science or chemistry when discussing identity. They did not explicitly mention confidence when unprompted, but instead described their mastery experiences, such as taking an exam, when responding to questions that inquired about performance/competence or attributes of a science or chemistry person. This theme differed slightly from the definition provided by the physics identity framework of performance/competence, where the construct was described as being reflective of student confidence. This evidence suggested that describing performance/competence in the form of mastery experiences instead of confidence may be more appropriate.

Table 8. Student quotes pertaining to educational experiences in relation to science or chemistry identity.

\begin{tabular}{ll}
\hline Student & Quote \\
\hline Elle & "Having good study habits [makes someone a chemistry person]... You have to know all the \\
& formulas, and how to apply the problems to those" \\
Steve & "You gotta be really careful with what you're doing, especially in chemistry lab. O-Chem lab was \\
& the most stressful thing in my life. It's just making sure you're paying attention to the instructions \\
& or making sure you're not putting the wrong things together and keeping track of it all." \\
Max & "I mean I've always been good at science I think it's something that I can be successful and I've \\
& always gotten mostly $\boldsymbol{A}$ 's and a couple B's in any scientific area..."
\end{tabular}




\begin{tabular}{|c|c|}
\hline Erica & $\begin{array}{l}\text { "...I'll bomb my first exam pretty bad, about } 50 \ldots \text { And that's when I study really hard. And the } \\
\text { pattern is, my second exam, I usually get more than } 90 \ldots \text { Yeah, I think that's definitely a setback. It } \\
\text { pushes me way behind, so then I have to go ahead and study old stuff and the new stuff, 'cause it's } \\
\text { cumulative." }\end{array}$ \\
\hline Barb & $\begin{array}{l}\text { "...The reason why I was taking biology last term and I'm taking chemistry now is 'cause I'm } \\
\text { retaking them from community college. So I just didn't really do as well as I wanted to when I was } \\
\text { in community college in those classes." }\end{array}$ \\
\hline Karen & $\begin{array}{l}\text { "Gen-chem was, I was really scared going into it so I studied really hard for the first exam and } \\
\text { then did obscenely well...." }\end{array}$ \\
\hline Erica & "I think they think I do well in it, so they [think I'm a science person]." \\
\hline Karen & "[My friends see me as a chemistry person] mainly because I was really good at it." \\
\hline
\end{tabular}

\section{Theoretical framework surrounding Theme 2}

Mastery Experiences

The construct of mastery experiences is a source of self-efficacy and was reflected in student

responses when they described the contribution of their educational experiences to their science or chemistry identity. Self-efficacy is defined as "people's judgments of their capabilities to organize and execute courses of action required to attain designated types of performances" (Bandura and National Inst of Mental Health, 1986). Social cognitive theory (SCT) emphasizes that perceived self-efficacy is directly correlated to behavioral change and is the foundation of human agency. When applied in a studentcentered context, SCT implies that self-efficacy guides students' actions which in turn can influence their motivation and affect.

Mastery experiences are experiences in which an individual is able to base their self-perception on successes and failures of specific tasks. This is the most influential source of self-efficacy because it provides the clearest evidence to whether an individual can succeed in future tasks (Bandura, 1997). An example of a mastery experience within the classroom is a student taking an exam. Exams occur multiple times within a course, providing students with the opportunity to learn and improve the outcomes in subsequent attempts. Several students mentioned mastery experiences, such as exams, or passing courses, when discussing their science or chemistry identity.

\section{Theme 3: Students gain information about identity through interactions with others.}

Students frequently mentioned interactions with others when discussing science or chemistry identity within the Recognition portion of the interview. Representative student quotes can be found within Table 9. There were three distinct ways that students described interacting with others as a form of recognition. First, students discussed interacting with others to negotiate their own identity through comparison of 
themselves with others. Erica compared herself to non-specific "others" who she saw as more or less advanced than herself in relation to chemistry. Nancy compared herself to her family when explaining why they recognize her as a science person. Steve compared himself to his peers when explaining how he isn't recognized as a chemistry person. Next, students mentioned being recognized by others when being approached for help or discussing science or chemistry in conversation. This was illustrated by Karen when she described her family approaching her for medical advice and Nancy when her friends asked her a question and she gave an in-depth response. Finally, students described being recognized, or not being recognized, as a science or chemistry person through encouragement or discouragement from others. Elle described her family verbalizing encouragement whereas Nancy described her peers verbalizing discouragement. Recognition by others as a science or chemistry person was dependent on interactions with others and this theme described multiple ways that those interactions occur. Two of these interactions, comparison to others and encouragement, aligned with the theoretically established constructs of vicarious experiences and verbal persuasion, respectively.

Table 9. Student quotes pertaining to their interactions with others to navigate their science or chemistry identity.

\begin{tabular}{|c|c|}
\hline Student & Quote \\
\hline Erica & $\begin{array}{l}\text { "There's clearly people who are far more advanced than I am, and then there's people who are far } \\
\text { behind. And I'm kind of in the middle, where I see myself in terms of chemistry." }\end{array}$ \\
\hline Nancy & $\begin{array}{l}\text { "I'm the only person in my family that actually is like, "Science!" And even all my little siblings are } \\
\text { like, either no school or sociology }\end{array}$ \\
\hline Steve & $\begin{array}{l}\text { "...I was like the only person in our study group who got a C and I was really bummed because it's } \\
\text { such an important class...like my other friends in my study group are just chemistry geniuses." }\end{array}$ \\
\hline Karen & $\begin{array}{l}\text { "I'm pre-med and...my family will literally just text me and be like, 'ey, this is going on with me. } \\
\text { What's wrong with me?" " }\end{array}$ \\
\hline Nancy & $\begin{array}{l}\text { "I always come up with weird quirky facts. Like, we'll be having a regular conversation and they'll } \\
\text { say something like trans-fatty acid or something, and then they'll be like, 'Well why is that bad for } \\
\text { you?' And then I'll be like, 'Well trans is like this,' 'and it's like, 'And then cis is, '..." }\end{array}$ \\
\hline Elle & "My mom, and my brother, and my dad have all said, 'No, you're good at science.' "' \\
\hline Nancy & "[My peers are] like, 'Oh, maybe you're not that good at this. How are you gonna get through it?" " \\
\hline
\end{tabular}

\section{Theoretical framework surrounding Theme 3}

Verbal Persuasion and vicarious experience

Verbal persuasion and vicarious experiences are two additional sources of self-efficacy. "People who

are persuaded verbally that they possess the capabilities to master given tasks are likely to mobilize greater sustained effort than if they harbor self-doubts and dwell on personal deficiencies when difficulties arise" (Bandura, 1997). Encouragement or discouragement from others as a form of recognition within the identity interviews aligned with verbal persuasion, as others were verbally 
encouraging or discouraging students to participate in science or chemistry. The other source of selfefficacy, vicarious experiences are used to judge an individual's self-efficacy based on watching others perform tasks. For many specific tasks, there are no absolute measures of adequacy. For example, if a student receives a score on an exam that is not a perfect score, they may not know if they performed adequately unless they compare scores with other students, as seen by Steve when he compared his grade of a "C" to other students within his study group.

There were multiple forms of recognition students described within the interviews. The established constructs of vicarious experiences and verbal persuasion aligned well with two forms of recognition. Targeting specific sources of recognition could be helpful in providing information on how to foster recognition and therefore science or chemistry identity.

\section{Theme 4: Participation in science or chemistry takes a certain type of person.}

The previous three themes contained additional information about interest, performance/competence, and recognition as described by the physics identity framework. This final theme was present throughout the interview but did not directly align with any of the previously described constructs. During interviews, students described science or chemistry people in two ways; those who had an innate talent for science or chemistry and those who were determined to succeed. Representative student quotes can be found within Table 10. Within the Attributes and Self-Recognition section, students would describe being a science or chemistry person as someone who has some type of trait that allows one to understand science or chemistry. For example, Max described a science person as someone with the ability to understand science and Elle described herself as lacking the ability to understand chemistry. By describing science and chemistry identities this way, students were describing who is equipped to be a science or chemistry person and inferred that it is an inherent trait. The second way students described a science or chemistry person was through hard work or determination. For example, within the Attributes and Self-Recognition section, Robin described that it takes grit and commitment to be a science person and Steve described a science person as someone who is driven to ask and answer questions about life. The two ways that students described certain types of people as being able to participate in science or chemistry aligned with the affective constructs of fixed and growth mindset. 
Table 10. Student quotes pertaining to the types of people who participate in science or chemistry.

\begin{tabular}{ll}
\hline Student & Quote \\
\hline Max & "Someone who's good at visualizing things that they can't see or understanding those concepts." \\
\cline { 2 - 3 } Elle & $\begin{array}{l}\text { "I think my brain just isn't equipped to be able to deal with those kinds of [chemistry] problems, } \\
\text { or concepts." }\end{array}$ \\
\cline { 2 - 2 } $\begin{array}{l}\text { Robin } \\
\text { Steve }\end{array}$ & $\begin{array}{l}\text { "I don't think it's a special skill per se, it's more about grit, just committing to [science]." } \\
\text { "It's kinda like, 'How do I work? Or how do we work?' So it's just having that drive to figure stuff } \\
\text { out." }\end{array}$ \\
\hline
\end{tabular}

\section{Theoretical framework surrounding Theme 4}

Mindset

Growth mindset is the belief that one has the ability to develop their intelligence (Dweck, 2013). The antithesis of growth mindset is fixed mindset, which is the belief that intelligence is fixed and cannot be developed. While determination is not directly interchangeable with growth mindset, it is an important part of growth mindset (Dweck, 2015). Students such as Robin and Steve mentioned drive and commitment. While this doesn't confirm that Robin and Steve had a growth mindset, it did suggest that they did not have a fixed mindset. In comparison, Max and Elle described a science or chemistry person as having a certain ability that helps them to understand science or chemistry. This suggested that a person has an inherent trait within them and suggested more of a fixed mindset. Mindset interventions have been shown to increase performance in underachieving students and are theorized to aid in persistence in academia (Dweck, 2009; Paunesku, et al., 2015; Claro, et al., 2016). Fixed vs. growth mindset may not have appeared in Carlone \& Johnson's (2007) science identity study because the women involved in the study were further along in their science careers. While mindset hasn't explicitly been discussed as an aspect of identity, it may be an important variable to consider in future studies of science and chemistry identity.

\section{Summary}

In response to research question one, four themes arose when students responded to questions pertaining to science and chemistry identity. These themes were then discussed in terms of their relation to other, more theoretically grounded, constructs in order to address research question two. The established constructs, with their definitions aligned to science and chemistry identity, are listed in Figure 2. Three of the four themes provided clarification to the descriptions of interest, performance/competence, and recognition as described by the physics identity framework. Within the interviews, interest was 
discussed in terms of students' feelings and values and their relation to science or chemistry. This description of interest aligned with the theory that interest has both feeling- and value-related components (Schiefele, 1991). In addition to feelings and value, students described different stages of interest, which supported the four-phase model of interest (Hidi and Renninger, 2006). Based on these alignments, the construct of interest was redefined as situational interest, where the orientation of students to science or chemistry was discussed through value- and feeling-related interest. Students discussed recognition in the terms of interactions with others. Two ways that these interactions occurred were through verbal persuasion and vicarious experiences (Bandura, 1977). Recognition was therefore divided into the two constructs of verbal persuasion and vicarious experiences. Verbal persuasion was defined as verbal recognition for being good at science or chemistry. Vicarious experiences were defined as recognition of self through comparison of others' experiences with science or chemistry. Performance/competence was discussed in terms of success within educational experiences. The types of successes described, e.g., course and exam grades, aligned with mastery experiences (Bandura, 1977). Mastery experiences were defined as experiences in which an individual is able to base their selfperception on successes and failures of specific tasks within the classroom. Within the fourth theme, students described science or chemistry people as either having an inherent trait that oriented them toward science or chemistry or as being determined to succeed within science or chemistry. This theme aligned with the theory of mindset (Dweck, 2013), where becoming a science or chemistry person is either dependent on an inherent trait or attained through determination. By exploring themes of identity formation and grounding them within theoretically sound constructs, we have taken the first step in creating a measure of identity to use within chemistry education. 
SCIENCE IDENTITY

(Carlone and Johnson 2007)
PHYSICS IDENTITY

(Hazari et. al., 2010)

\section{SCIENCE/CHEMISTRY IDENTITY}

\section{Mindset}

Becoming a science or chemistry person is either dependent on an inherent trait or is attained through determination

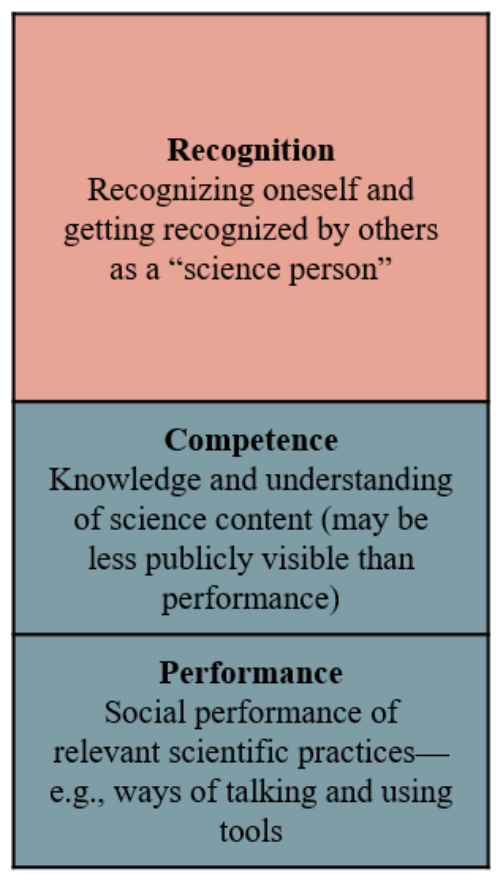

Interest

Desire/curiosity to think about and understand physics

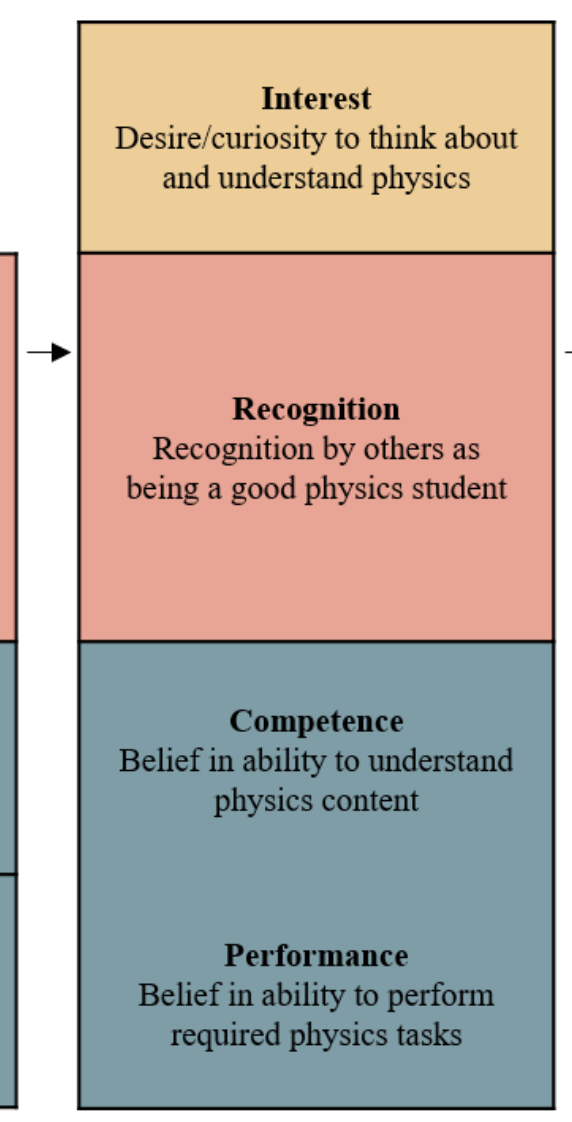

\section{Situational Interest} The orientation of a student to science or chemistry through value- and feeling-related interest

Verbal Persuasion Verbal recognition for being good at science or chemistry

Vicarious Experiences Recognition of self through comparison of others' experiences with science or chemistry

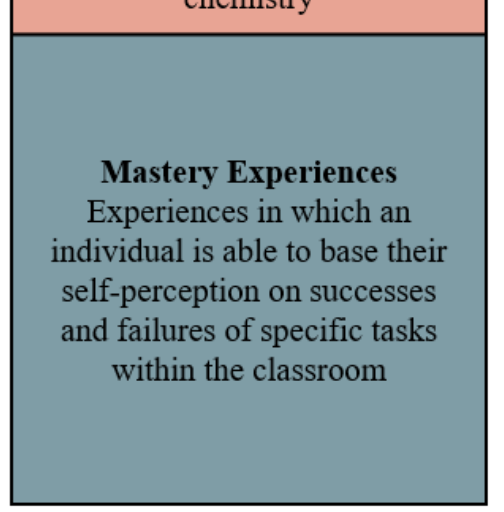

Figure 2. The alignment and modification of identity theories

\section{Conclusions and Limitations}

Identity has been theorized to be an important factor in student persistence (Chang, et al., 2011; Estrada, et al., 2011; President's Council of Advisors on Science and Technology, 2012; Graham, et al., 2013; Flowers and Banda, 2016). However, to assess identity it first needs to be contextualized and well defined. This study built upon the work of Hazari et al. (2010) by further investigating the sub-constructs of the physics identity framework: interest, recognition, and performance/competence. Student interviews based on prior conceptualization of these constructs elicited responses that were aligned with the constructs of situational interest, verbal persuasion, vicarious experiences, mastery experiences, and 
mindset. Developing and collecting information reflecting these theoretically grounded constructs could potentially provide a more precise understanding of identity. By rooting the identity sub-constructs within these psychological constructs, we have taken the first step to creating a measure that can inform students' science or chemistry identity formation. In the future, having specific construct measures will provide insight to specific target variables for identity interventions.

The sources of self-efficacy have been previously hypothesized to align with science identity, further supporting the alignment of performance/competence with mastery experiences and recognition with verbal persuasion and vicarious experiences. Flowers and Banda (2016) have argued that these sources of self-efficacy are a crucial component for cultivating a science identity, specifically among minority students. Cultivating a strong self-efficacy for tasks within science can help students to believe they can be successful in the field of science. Vicarious experiences were mentioned as the source of self-efficacy missing from Carlone \& Johnson's (2007) original science identity theory and is proposed to be a large contributor to science identity for students of color.

There were a few limitations within this study. First, the distinction between science and chemistry identity was not investigated. While there were no differing themes between wording when students responded to questions about both science and chemistry identity, future studies should explore the nuances between the two identities. Next, student interviews took place at one university with limited demographics. While evidence of data saturation was present within this sample, interviewing students at multiple universities or with more diverse demographics would provide additional support for the constructs of science and chemistry identity defined within this study. Qualitative studies provide rich data that can aid in the development or elucidation of theory, but alone, do not provide evidence for generalization. The next step in providing more robust support for a science or chemistry identity framework would be to distribute surveys containing the constructs found within the study to test their psychometric functioning. Finally, mastery experiences, vicarious experiences, and verbal persuasion were not discussed as a source of self-efficacy within the interviews but rather a direct source of identity. Future work should explore whether these constructs are direct sources of identity or if they are mediated by self-efficacy. 


\section{Appendix}

\section{List of questions and demographics used in semi-structured interview protocol}

Bracketed words were replaced with the word "chemistry" for the discipline-specific version of the question.

Section I: Attributes of a science or chemistry person and self-recognition

- What do you think makes someone a [science] person?

- Do you see yourself as a [science] person?

- Can you point me to some specifics or examples that would help me understand why you see (or don't see) yourself in this way?

\section{Section II: Recognition by others}

- Do your friends see you as a [science] person?

○ How do you know they see (or don't see you) this way?

- Do your peers see you as a [science] person?

- Who do you consider your peers?

- How do you know they see (or don't see you) this way?

- Do other people who are important to you see you as a [science] person?

○ Who did you think of when responding to this question?

- How do you know they see (or don't see you) this way?

- With regard to others seeing you as a science or chemistry person are their individuals or groups we didn't discuss that you would like to mention?

- Have you had experiences in which you were recognized as a [science] person?

\section{Section III: Performance/Competence}

- How confident are you that you can understand [science] in class?

- What is your confidence based on?

- How confident are you that you can understand [science] outside of class?

$\circ$ What is your confidence based on?

- Do you understand concepts that you've studied in [science]?

- What does "understand concepts" mean to you?

- Do you do well on exams in [science]?

o What does doing well mean to you?

- Do others ask you for help in [science]?

- Can you give me some examples of who asks you for help?

- Have you overcome any setbacks in [science]?

○ What types? How did you overcome them?

\section{Section IV: Interest}

- Are you interested in learning more about [science]?

- What about [science] makes you interested/not interested?

- Do you enjoy learning [science]?

$\circ$ What about [science do you enjoy/not enjoy?

- Do you find fulfillment in doing [science]?

$\circ \quad$ What about doing [science] makes you feel fulfilled? 


\section{Demographics}

- What is your university status (e.g., undergrad, transfer student, post-bac)?

- What is the gender you identify as?

- What is the race/ethnicity you identify with?

\section{References}

Abrams D. and Hogg M. A., (1990), Social identity theory: Constructive and critical advances, New York, NY, US: Springer-Verlag Publishing.

Ainley M., (2007), in Emotion in Education, eds. Schutz P. A. and Pekrun R., Burlington: Academic Press, pp. 147-163.

Bandura A., (1977), Self-efficacy: Toward a unifying theory of behavioral change, Psychol. Rev., 84, 191-215.

Bandura A., (1997), Self-efficacy: The exercise of control, New York, NY, US: Worth Publishers.

Bandura A., Barbaranelli C., Caprara G. V. and Pastorelli C., (2001), Self-efficacy beliefs as shapers of children's aspirations and career trajectories, Child Dev., 72, 187-206.

Bandura A. and National Inst of Mental Health, (1986), Prentice-Hall series in social learning theory: Social foundations of thought and action: A social cognitive theory, Englewood Cliffs, New Jersey, USA: Prentice-Hall, Inc.

Bonous-Hammarth M., (2000), Pathways to Success: Affirming Opportunities for Science, Mathematics, and Engineering Majors, J. Negro Educ., 69, 92-111.

Braun V. and Clarke V., (2006), Using thematic analysis in psychology, Qual. Res. Psychol., 3, 77-101.

Braun V., Clarke V., Hayfield N. and Terry G., (2019), in Handbook of Research Methods in Health Social Sciences, ed. Liamputtong P., Singapore: Springer Singapore, pp. 843-860.

Brickhouse N. W., Lowery P. and Schultz K., (2000), What Kind of a Girl Does Science? The Construction of School Science Identities, J. Res. Sci. Teach., 37, 441-458.

Burke P. J. and Stets J. E., (2009), Identity theory, New York, New York, USA: Oxford University Press.

Carlone H. B. and Johnson A., (2007), Understanding the science experiences of successful women of color: Science identity as an analytic lens, J. Res. Sci. Teach., 44, 1187-1218.

Cass C. A. P., Hazari Z., Cribbs J., Sadler P. M. and Sonnert G., Examining the impact of mathematics identity on the choice of engineering careers for male and female students, Rapid City, South Dakota, USA, 2011.

Chang M. J., Eagan M. K., Lin M. H. and Hurtado S., (2011), Considering the Impact of Racial Stigmas and Science Identity: Persistence Among Biomedical and Behavioral Science Aspirants, $J$. Higher Educ., 82, 564-596.

Chemers M. M., Zurbriggen E. L., Syed M., Goza B. K. and Bearman S., (2011), The role of efficacy and identity in science career commitment among underrepresented minority students, J. Soc. Issues, 67, 469-491.

Cheng H., Potvin G., Khatri R., Kramer L. H., Lock R. M. and Hazari Z., Examining physics identity development through two high school interventions, Washington, DC, USA, 2018.

Childers G. and Jones M. G., (2017), Learning from a distance: high school students' perceptions of virtual presence, motivation, and science identity during a remote microscopy investigation, Int. J. Sci. Educ., 39, 257-273.

Claro S., Paunesku D. and Dweck C. S., (2016), Growth mindset tempers the effects of poverty on academic achievement, Proc. Natl. Acad. Sci. U.S.A., 113, 8664-8668.

Cribbs J. D., Hazari Z., Sonnert G. and Sadler P. M., (2015), Establishing an Explanatory Model for Mathematics Identity, Child Dev., 86, 1048-1062.

Davidoff L. and Hall C., (2013), Family fortunes: Men and women of the English middle class, 17801850, Milton Park, Abingdon, Oxon: Routledge.

Dweck C. S., (2009), Can we make our students smarter?, Education Canada, 49, 56-61. 
Dweck C. S., (2013), Self-theories: Their role in motivation, personality, and development, New York, NY, USA: Psychology press.

Dweck C. S., (2015), Carol Dweck revisits the growth mindset, Education Week, 35, 20-24.

Eccles J. S., (2007), in Why aren't more women in science?: Top researchers debate the evidence., Washington, DC, USA: American Psychological Association, pp. 199-210.

Estrada M., Hernandez P. R. and Schultz P. W., (2018), A longitudinal study of how quality mentorship and research experience integrate underrepresented minorities into STEM careers, CBE Life. Sci. Educ., 17.

Estrada M., Woodcock A., Hernandez P. R. and Schultz P. W., (2011), Toward a model of social influence that explains minority student integration into the scientific community, J. Educ. Psychol., 103, 206.

Flowers A. M. and Banda R., (2016), Cultivating science identity through sources of self-efficacy, J. for Multicultural Educ., 10, 405-417.

Furr R. M. and Bacharach V. R., (2008), Psychometrics: an introduction, Thousand Oaks, California, USA: Sage Publications.

Godwin A. and Potvin G., (2013), Chemical Engineering Students: A Distinct Group among Engineers, Chem. Eng. Educ., 47, 145-153.

Godwin A., Potvin G. and Hazari Z., The Development of Critical Engineering Agency, Identity, and the Impact of Engineering Career Choices, Atlanta, Georgia, USA, 2013.

Godwin A., Potvin G., Hazari Z. and Lock R., Understanding engineering identity through structural equation modeling, Oklahoma City, Oklahoma, USA, 2013.

Godwin A., Potvin G., Hazari Z. and Lock R., (2016), Identity, Critical Agency, and Engineering: An Affective Model for Predicting Engineering as a Career Choice, J. Eng. Educ., 105, 312-340.

Graham M. J., Frederick J., Byars-Winston A., Hunter A.-B. and Handelsman J., (2013), Increasing Persistence of College Students in STEM, Science, 341, 1455.

Guest G., Bunce A. and Johnson L., (2006), How Many Interviews Are Enough?:An Experiment with Data Saturation and Variability, Field Methods, 18, 59-82.

Hazari Z., Sonnert G., Sadler P. M. and Shanahan M.-C., (2010), Connecting high school physics experiences, outcome expectations, physics identity, and physics career choice: A gender study, J. Res. Sci. Teach., 47, 978-1003.

Hidi S. and Renninger K. A., (2006), The four-phase model of interest development, Educ. Psychol., 41, 111-127.

Kline R. B., (2016), Principles and Practice of Structural Equation Modeling, New York, New York, USA: The Guilford Press.

Krapp A., (2007), An educational-psychological conceptualisation of interest, Int. J. Educ. Vocat. Guid., 7, 5-21.

Lent R. W., Brown S. D. and Hackett G., (1994), Toward a Unifying Social Cognitive Theory of Career and Academic Interest, Choice, and Performance, J. Vocat. Behav., 45, 79-122.

Lorber J., (1994), Paradoxes of gender, Binghamton, New York, USA: Yale University Press.

National Research Council, Discipline-based education research: Understanding and improving learning in undergraduate science and engineering, National Academies Press, Washington, D.C., 2012.

Paunesku D., Walton G. M., Romero C., Smith E. N., Yeager D. S. and Dweck C. S., (2015), Mind-Set Interventions Are a Scalable Treatment for Academic Underachievement, Psychol. Sci., 26, 784793.

Penner A. M., (2015), Gender inequality in science, Science, 347, 234-235.

Potvin G. and Hazari Z., The Development and Measurement of Identity across the Physical Sciences, Portland, Oregon, USA, 2013.

President's Council of Advisors on Science and Technology, Engage to Excel: Producing One Million Additional College Graduates with Degrees in Science, Technology, Engineering, and Mathematics. Report to the President, 2012.

Renninger K. A. and Hidi S., (2011), Revisiting the Conceptualization, Measurement, and Generation of Interest, Educ. Psychol., 46, 168-184. 
Robnett R. D., Chemers M. M. and Zurbriggen E. L., (2015), Longitudinal associations among undergraduates' research experience, self-efficacy, and identity, J. Res. Sci. Teach., 52, 847-867.

Sansone C., Fraughton T., Zachary J. L., Butner J. and Heiner C., (2011), Self-regulation of motivation when learning online: the importance of who, why and how, Educ. Technol. Res. Dev., 59, 199212.

Schiefele U., (1991), Interest, Learning, and Motivation, Educ. Psychol., 26, 299.

Sellers R. M., Smith M. A., Shelton J. N., Rowley S. A. J. and Chavous T. M., (1998), Multidimensional Model of Racial Identity: A Reconceptualization of African American Racial Identity, Pers. Soc. Psychol. Rev., 2, 18-39.

Seymour E., Hewitt N. M. and Friend C. M., (1997), Talking about leaving: Why undergraduates leave the sciences, Boulder, Colorado, USA: Westview Press.

Shanahan M. C., (2009), Identity in science learning: exploring the attention given to agency and structure in studies of identity, Stud. Sci. Educ., 45, 43-64.

Shedlosky-Shoemaker R. and Fautch J. M., (2015), Who Leaves, Who Stays? Psychological Predictors of Undergraduate Chemistry Students' Persistence, J. Chem. Educ., 92, 408-414.

Silvia P. J., (2005), What Is Interesting? Exploring the Appraisal Structure of Interest, Emotion, 5, 89102.

Stets J. E., Brenner P. S., Burke P. J. and Serpe R. T., (2017), The science identity and entering a science occupation, Soc. Sci. Res., 64, 1-14.

Tourangeau R. and Yan T., (2012), in APA handbook of research methods in psychology, Vol 2: Research designs: Quantitative, qualitative, neuropsychological, and biological., eds. Cooper H., Camic P. M., Long D. L., Panter A. T., Rindskopf D. and Sher K. J., Washington, DC, USA: American Psychological Association, ch. 14, pp. 227-251.

Verdín D., Godwin A., Kirn A., Benson L. and Potvin G., Understanding How Engineering Identity and Belongingness Predict Grit for First-Generation College Students, Crystal City, Virginia, USA, 2018.

Vincent-Ruz P. and Schunn C. D., (2018), The nature of science identity and its role as the driver of student choices, Int. J. of STEM Educ., 5, 48. 